\title{
Intraoperative frozen section consultation- an audit in a tertiary care hospital
}

\author{
A. Sathish Selvakumar', V. Rajalakshmi',*, K. Meenakshi Sundaram ${ }^{3}$ \\ ${ }^{\mathbf{1}}$ Assistant Professor, ${ }^{2}$ Professor and HOD, ${ }^{3}$ Associate Professor, Dept. of Pathology, ESIC Medical College and PGIMSR, \\ Chennai, Tamil Nadu, India
}

*Corresponding Author:

Email: raji_path@rediffmail.com

Received: $26^{\text {th }}$ December, 2017

Accepted: $13^{\text {th }}$ February, 2018

\begin{abstract}
Introduction: Frozen section (FS) helps the surgeon in the surgical management of the patient by helping in the intraoperative diagnosis of tumors, margins and lymphnode assessment, and organ identification. Audits of the frozen section consultations help in identifying the pitfalls and to carry out appropriate preventive measures for its optimal usage. We report the results of the study of our FS consultations.

Materials and Methods: A retrospective study of 518 specimens from 132 consecutive cases of FS consultations was carried out. The FS report and formalin fixed tissue reports were compared and analyzed. The results were categorized into concordant, discordant and deferred consultations. Causes of discrepancy were analysed and diagnostic accuracy, diagnostic error rates, sensitivity, specificity, indications, tissue type, turnaround time and limitations were noted.

Results: An average of 3.92 specimens per patient was received with 80(60.61\%) males and 52(39.39\%) females. Age ranged from 15 to 80 years. Male and female general surgical departments were the major contributors with $64(48.48 \%)$ and 25 $(18.94 \%)$ consultations respectively. Oropharyngolaryngeal region $(48.84 \%)$ was the main site sampled. The main indication was margin status assessment (52.27\%). Accuracy rate was $98.65 \%$ with an error rate of $1.35 \%$ was observed. The discordant cases had misinterpretation error in 5 cases and sampling errors in the remaining 2 cases. Three cases $(0.58 \%)$ were deferred. Sensitivity (90.91\%) and specificity (96.59\%) was obtained.
\end{abstract}

Conclusions: The study turned out as a quality check and identified the areas requiring improvement to reduce the error rates.

Keywords: Frozen section, Retrospective study, Accuracy, Error, Margin status, Sensitivity.

\section{Introduction}

Intraoperative "frozen section" (FS) also termed as fresh tissue diagnosis, quick section, cryogenic sectioning, cryosection, cryoultramicrotomy, intraoperative pathologic diagnosis and intraoperative consultation is an investigation which helps in guiding the surgeon to plan for further management at the time of operation. ${ }^{1,2}$ The credit for standardising the technique goes to Dr. Louis B Wilson in 1905 at the Mayo Clinic in Rochester, USA. ${ }^{2}$ This created a new era in intraoperative diagnosis that has evolved after the development of the cryostat equipment. ${ }^{2}$ Other methods such as squash smear cytology; fluid cytology and imprint cytology also help in the intraoperative diagnoses. ${ }^{1} \mathrm{FS}$ is a rapid technique that contributes in the primary diagnosis of a lesion, inflammatory or neoplastic, benign or malignant, status of margins, organ identification and disease extension. ${ }^{3,4}$ However the limitations and indications vary according to the individual organs. ${ }^{3,4}$ A good rapport with the operating surgeon, better clinical correlation, knowledge about the preoperative and per-operative findings, and limitations of the method helps in getting the maximum yield of the FS. ${ }^{1}$ Errors should be identified and analysed, which can help to carry out appropriate preventive measures. ${ }^{5,6} \mathrm{We}$ report the results of the audit of our FS consultations data of 5 years and discuss about the diagnostic accuracy, common reasons behind misdiagnoses, overall sensitivity and specificity and the limitations of FS consultations.

\section{Materials and Methods}

This is a retrospective study of 518 biopsy specimens from 132 consecutive cases received for intra-operative FS consultations from surgical departments over a period of 5 years (December 2012 to September 2017) in the department of pathology. Patient confidentiality was maintained and approval from our institutional ethics committee was obtained. The data was obtained from our dedicated manual records. Fresh tissue samples were sent in a clean container properly labelled along with requisition form carrying necessary clinical details and indications. Appointment for a FS consultation was usually fixed on the previous day by the surgical departments requesting for the investigation and a most experienced lab technician was available for the frozen section (FS) technique.

Processing of Frozen Section Tissue and its Remains: Fresh unfixed tissue sent was gross examined and appropriate sections were taken. Frozen sectioning was done on the cryostat (Leica, CM1850, Germany) machine (Fig. 1). The tissue sections were cut at temperature between $-18{ }^{\circ} \mathrm{c}$ to $-24{ }^{\circ} \mathrm{C}$ according to the nature of the tissue. Precautions were taken to avoid rapid freezing and subsequent artefacts. Minimum of 
two sections were examined for each frozen tissue. The sections were immediately fixed and stained. A consensus of the diagnosis was made by 2 pathologists, including a senior pathologist and was immediately conveyed to the operating surgeon over the intercom. The turnaround time (TAT) was noted down from the time of receipt of the specimen to the time of delivery of the report to the surgeon. The frozen remains were then formalin fixed, processed in automated tissue processor (Leica TP1030, Germany), paraffin embedded and stained with H\&E stain. The FS report and the tissue remains formalin fixed paraffin embedded (FFPE) report were then reviewed by two pathologist. The results were categorized into three groups: concordant, discordant and deferred consultations. Deferred cases were defined as indeterminate diagnoses at the time of frozen section examination. Discordant cases were reviewed and causes of discrepancy were analysed and recorded. The diagnostic accuracy, error rates, sensitivity and specificity were calculated. Also the indications, organ/tissue type submitted for FS, limitations of frozen sectioning were noted.

\section{Results}

We received an average of 3.92 specimens per patient of which $80(60.61 \%)$ were males and $52(39.39 \%)$ were females. The age range was wide which varied from 15 years to 80 years old. (Fig. 2). The male and female general surgical departments were the major contributors for FS consultations with a total of $64(48.48 \%)$ and $25(18.94 \%)$ consultations constituting about $67.42 \%$ of all the consultations while the rest was contributed by Obstetrics and gynaecology, Oto-rhino-laryngology, Dental, Orthopaedics and Ophthalmology departments less frequently (Table 1). Of the 518 specimens 253 specimens (48.84\%) were from the oropharyngolaryngeal regions, 60 specimens
$(11.58 \%)$ were from the lymph node and 47 specimens were from the soft tissue $(9.07 \%)$ (Table 2). The major indication for FS was to assess the margins status. A total of 69 consultations $(52.27 \%)$ were sent for the margin status assessment predominantly from the oropharyngolaryngeal areas. A further 26 consultations $(19.69 \%)$ were sent to detect the presence of lymphnode and organ metastases, 18 consultations $(13.64 \%)$ were for the primary intraoperative diagnoses which consisted of ovarian masses, thyroid swelling, salivary gland neoplasms, colonic growth and parathyroid lesions. Fourteen (10.61\%) consultations were for the confirmation of malignancy while 5 consultations $(3.79 \%)$ were from chronic hip arthritis, revision total hip replacement, breast abscess, pancreatic cyst wall and ileocaecal tuberculous infection to assess the severity of inflammation present and presence of infection. (Fig. 3). During the period of study, 5 qualified histopathologists were always available and performed the intraoperative diagnostic consultation. The frozen section reports (518 specimens) were compared to the permanent sections reports. An overall accuracy rate of $98.65 \%$ obtained with an error rate of $1.35 \%$ was noted. There were 511 concordant cases and 7 discordant cases. The discordant cases had 3 false positive cases and 4 false negative cases. The review of these 7 frozen sections showed misinterpretation error in 5 cases and sampling error in the remaining 2 cases. In the latter 2 cases, lesion was present in the permanent section of the main specimen. Three cases $(0.58 \%)$ one each from the ovary, larynx and lymphnode were deferred (Table 3,4). Sensitivity (true positive/true positive + false negative) of $90.91 \%$ and specificity (true negative/true negative + false positive) of $96.59 \%$ (Table 4) was obtained. No attempt was made to assess the difference in accuracy rate of the various pathologists.

Table 1: Different departments that had frozen section consultations

\begin{tabular}{|l|c|c|}
\hline \multicolumn{1}{|c|}{ Department } & No. of patients FS consultations & No. of specimens \\
\hline Dental & $5(3.79 \%)$ & $25(4.83 \%)$ \\
\hline ENT & $20(15.15 \%)$ & $87(16.80 \%)$ \\
\hline Female Surgical Wing & $25(18.94 \%)$ & $95(18.34 \%)$ \\
\hline Male Surgical Wing & $64(48.48 \%)$ & $270(52.12 \%)$ \\
\hline Obstetrics and Gynecology & $12(9.09 \%)$ & $27(5.21 \%)$ \\
\hline Orthopedics & $5(3.79 \%)$ & $13(2.51 \%)$ \\
\hline Ophthalmology & $1(0.76 \%)$ & $1(0.19 \%)$ \\
\hline Total & 132 & 518 \\
\hline
\end{tabular}

Table 2: List of sites that were sampled for intraoperative frozen section consultation

\begin{tabular}{|l|c|c|c|c|c|}
\hline S. No & Site & No. of Consultations & \% & No. of Specimens & \% \\
\hline 1. & Colon and rectum & 5 & $3.79 \%$ & 1 & $0.19 \%$ \\
\hline 2. & Penis & 4 & $3.03 \%$ & 8 & $1.54 \%$ \\
\hline 3. & Uterus with Cx & 3 & $2.27 \%$ & 2 & $0.39 \%$ \\
\hline 4. & Ovary & 9 & $6.80 \%$ & 26 & $5.02 \%$ \\
\hline 5. & Salivary gland & 4 & $3.03 \%$ & 20 & $3.86 \%$ \\
\hline
\end{tabular}




\begin{tabular}{|l|c|c|c|c|c|}
\hline 6. & Thyroid & 12 & $9.09 \%$ & 15 & $2.9 \%$ \\
\hline 7. & Oropharynx & 29 & $21.97 \%$ & 247 & $47.68 \%$ \\
\hline 8. & Soft tissue & 8 & $6.06 \%$ & 34 & $6.56 \%$ \\
\hline 9. & Bones and joint & 6 & $4.55 \%$ & 13 & $2.51 \%$ \\
\hline 10. & Breast & 5 & $3.79 \%$ & 12 & $2.32 \%$ \\
\hline 11. & Stomach & 7 & $5.30 \%$ & 15 & $2.9 \%$ \\
\hline 12. & Skin & 7 & $5.30 \%$ & 18 & $3.47 \%$ \\
\hline 13. & Pancreas & 1 & $0.76 \%$ & 2 & $0.39 \%$ \\
\hline 14. & Parathyroid & 2 & $1.52 \%$ & 7 & $1.35 \%$ \\
\hline 15. & Nasal and sinus cavities & 6 & $4.55 \%$ & 22 & $4.25 \%$ \\
\hline 16. & Larynx & 1 & $0.76 \%$ & 6 & $1.16 \%$ \\
\hline 17. & Lymphnodes & 18 & $13.64 \%$ & 60 & $11.58 \%$ \\
\hline 18. & Nerve & 3 & $2.27 \%$ & 5 & $0.97 \%$ \\
\hline 19. & Eye & 1 & $0.76 \%$ & 4 & $0.77 \%$ \\
\hline 20. & Appendix & 1 & $0.76 \%$ & 1 & $0.19 \%$ \\
\hline Total & & 132 & $100 \%$ & 518 & $100 \%$ \\
\hline
\end{tabular}

Table 3: Samples which had discordant results with permanent histology and the cause of the error

\begin{tabular}{|l|c|c|c|c|}
\hline S. No & Sample type & Frozen reported as & $\begin{array}{c}\text { Frozen tissue and } \\
\text { remnant tissue } \\
\text { histology }\end{array}$ & Cause of the error \\
\hline 1. & Oral cancer for margin status & Positive & Discordant (Negative) & Interpretation error \\
\hline 2. & Oral cancer for margin status & Negative & Discordant (Positive) & Interpretation error \\
\hline 3. & Oral cancer for margin status & Positive & Discordant (Negative) & Interpretation error \\
\hline 4. & Oral cancer for margin status & Negative & Positive & Interpretation error \\
\hline 5. & $\begin{array}{c}\text { Ovarian tumor for primary } \\
\text { diagnosis }\end{array}$ & Negative & $\begin{array}{c}\text { Discordant (Benign } \\
\text { epithelial tumor) }\end{array}$ & Sampling error \\
\hline 6. & $\begin{array}{c}\text { Endometrial curettings for } \\
\text { primary diagnosis }\end{array}$ & $\begin{array}{c}\text { Benign (Proliferative } \\
\text { endometrium) }\end{array}$ & $\begin{array}{c}\text { Discordant (Hyperplastic } \\
\text { endometrium) }\end{array}$ & Interpretation error \\
\hline 7. & $\begin{array}{c}\text { Bone tumor for primary } \\
\text { diagnosis }\end{array}$ & Negative & Discordant & Sampling error \\
\hline
\end{tabular}

Table 4: Various specimens received for frozen section with the comparative diagnostic accuracy analysis of frozen with permanent sections and the deferred cases

\begin{tabular}{|l|c|c|c|c|}
\hline \multicolumn{1}{|c|}{ Nature of specimens processed } & Number of specimens & Concordant & Discordant & Deferred \\
\hline Colon and rectum & $1(0.19 \%)$ & 1 & - & - \\
\hline Penis & $8(1.54 \%)$ & 8 & - & - \\
\hline Uterus with Cervix & $2(0.39 \%)$ & 1 & 1 & - \\
\hline Ovary & $26(5.02 \%)$ & 25 & 1 & 1 \\
\hline Salivary gland & $20(3.86 \%)$ & 20 & - & - \\
\hline Thyroid & $15(2.9 \%)$ & 15 & - & - \\
\hline Oropharynx & $247(47.68 \%)$ & 243 & 4 & - \\
\hline Soft tissue & $34(6.56 \%)$ & 34 & - & - \\
\hline Bones and joint & $13(2.51 \%)$ & 12 & 1 & - \\
\hline Breast & $12(2.32 \%)$ & 12 & - & - \\
\hline Stomach & $15(2.9 \%)$ & 15 & - & - \\
\hline Skin & $18(3.47 \%)$ & 18 & - & - \\
\hline Pancreas & $2(0.39 \%)$ & 2 & - & - \\
\hline Parathyroid & $7(1.35 \%)$ & 7 & - & - \\
\hline Nasal and sinus cavities & $22(4.25 \%)$ & 22 & - & - \\
\hline Larynx & $6(1.16 \%)$ & 6 & - & 1 \\
\hline Lymphnodes & $60(11.58 \%)$ & 60 & - & 1 \\
\hline Nerve & $5(0.97 \%)$ & 5 & - & - \\
\hline eye & $4(0.77 \%)$ & 4 & - & - \\
\hline
\end{tabular}




\begin{tabular}{|l|c|c|c|c|}
\hline Appendix & $1(0.19 \%)$ & 1 & - & - \\
\hline Total & $518(100 \%)$ & $511(98.65 \%)$ & $7(1.35 \%)$ & $3(0.58 \%)$ \\
\hline
\end{tabular}

Table 5: Comparison of frozen section discordant rates with other studies

\begin{tabular}{|l|c|c|c|c|}
\hline Authors & $\begin{array}{c}\text { Study period } \\
\text { (Year) }\end{array}$ & Number of cases & Concordance rate & $\begin{array}{c}\text { Discordance } \\
\text { Rate\% }\end{array}$ \\
\hline Patil P et al; ${ }^{(3)}$ & 2 & 100 & 96.9 & 3.1 \\
\hline Roy S et al; ${ }^{(9)}$ & 9 months & 327 & 97.6 & 2.4 \\
\hline Shreshtha S et al; ${ }^{(11)}$ & 5 & 404 & 94.6 & 5.4 \\
\hline Chbani et al; ${ }^{(12)}$ & 1 & 261 & 95 & 5 \\
\hline Present study & 5 & 132 & 94.70 & 5.30 \\
\hline
\end{tabular}

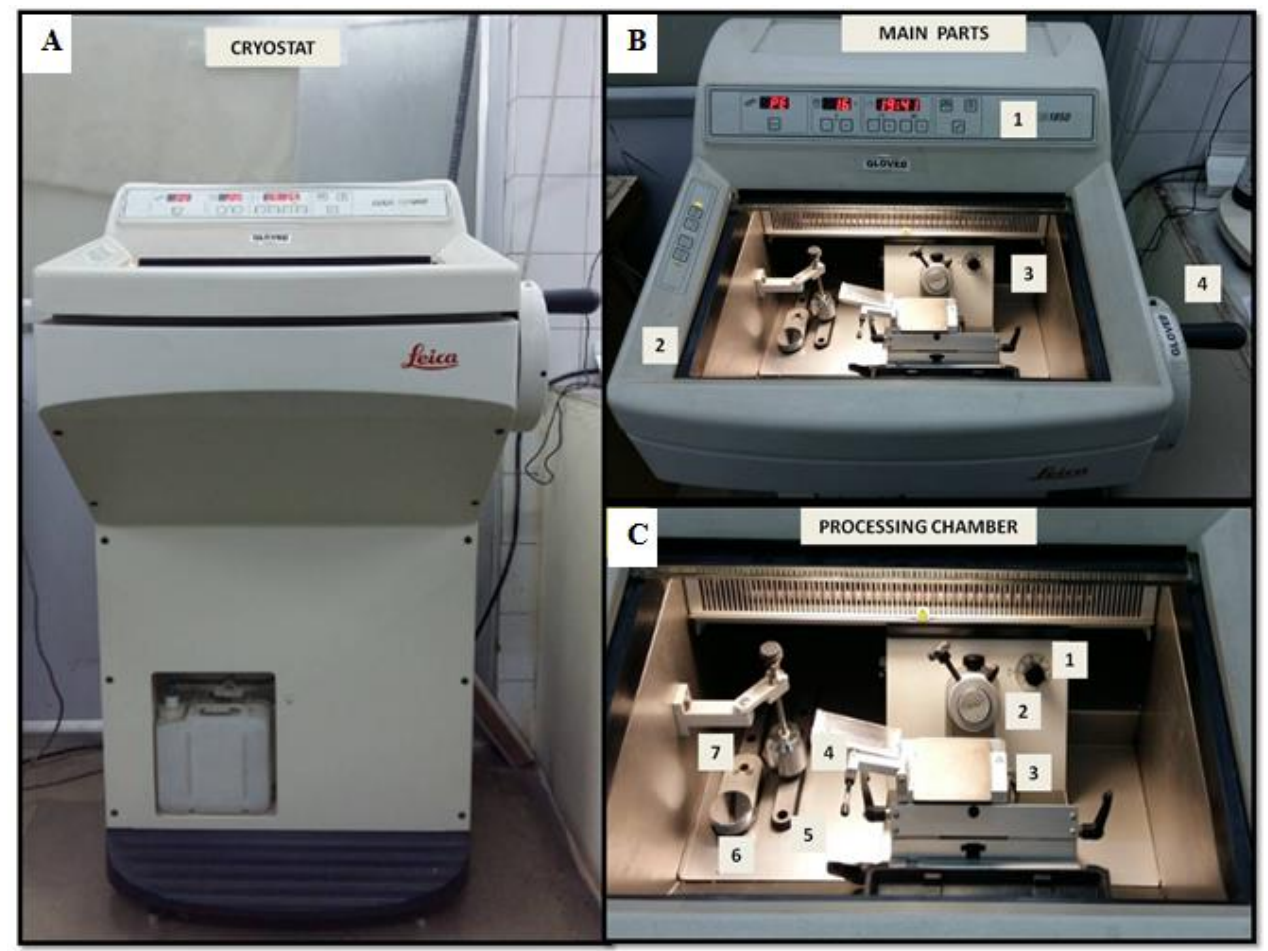

Fig 1: A): Cryostat CM1850 (GERMANY) B): Main parts 1. Control Panel I.; 2. Control Panel II.; 3. Tissue processing chamber; 4. Handle; C): Processing chamber 1. Section thickness setting knob; 2. Specimen disc holder; 3. Knife holder; 4. Stationary heat extractor; 5. Quick freeze shelf; 6. Parking station; 7. Peltier element

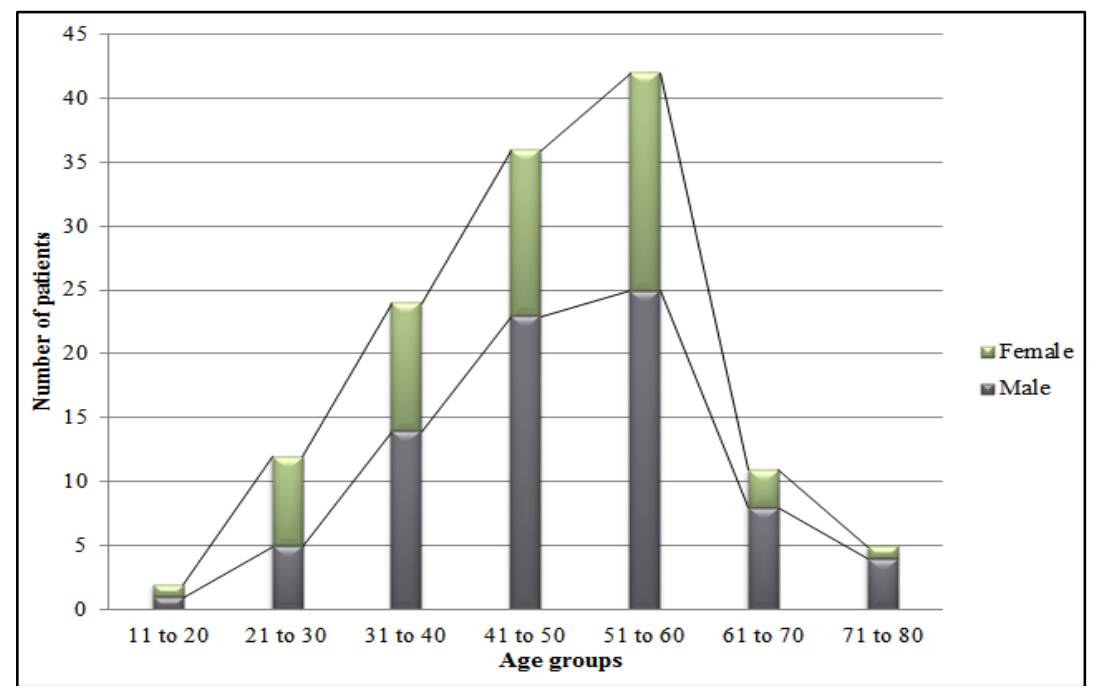


Fig. 2: Age distribution of patients with frozen section

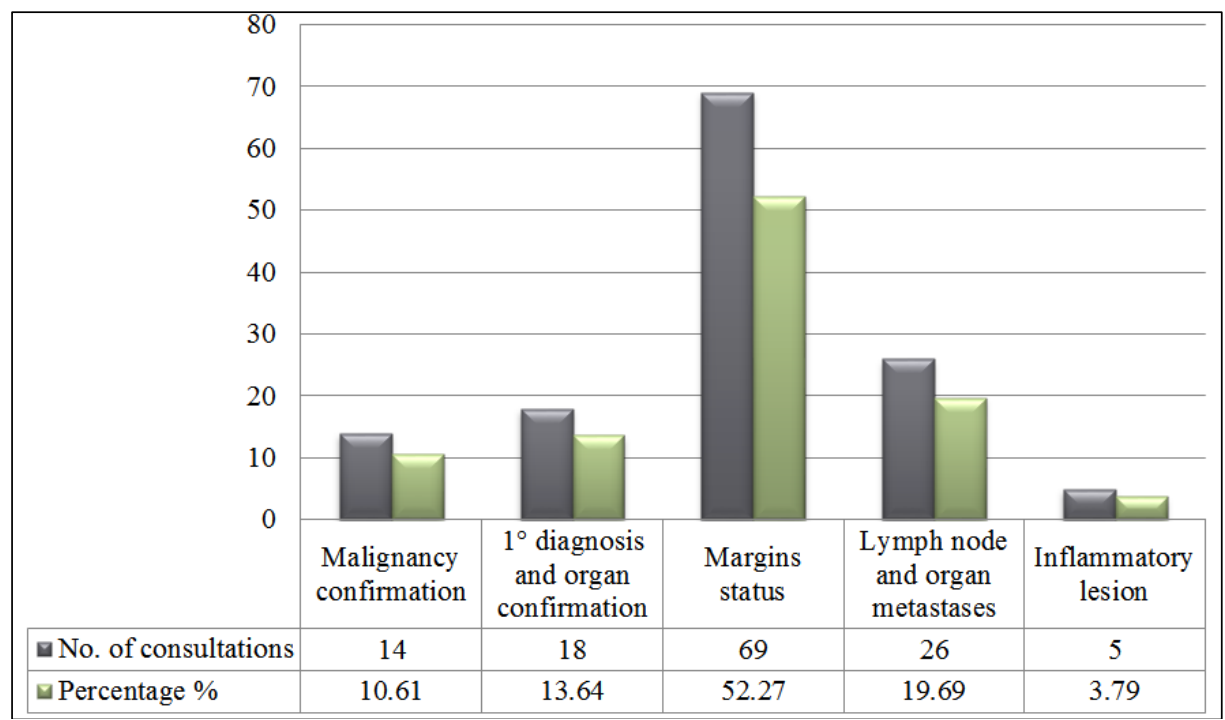

Fig. 3: Indications for frozen section

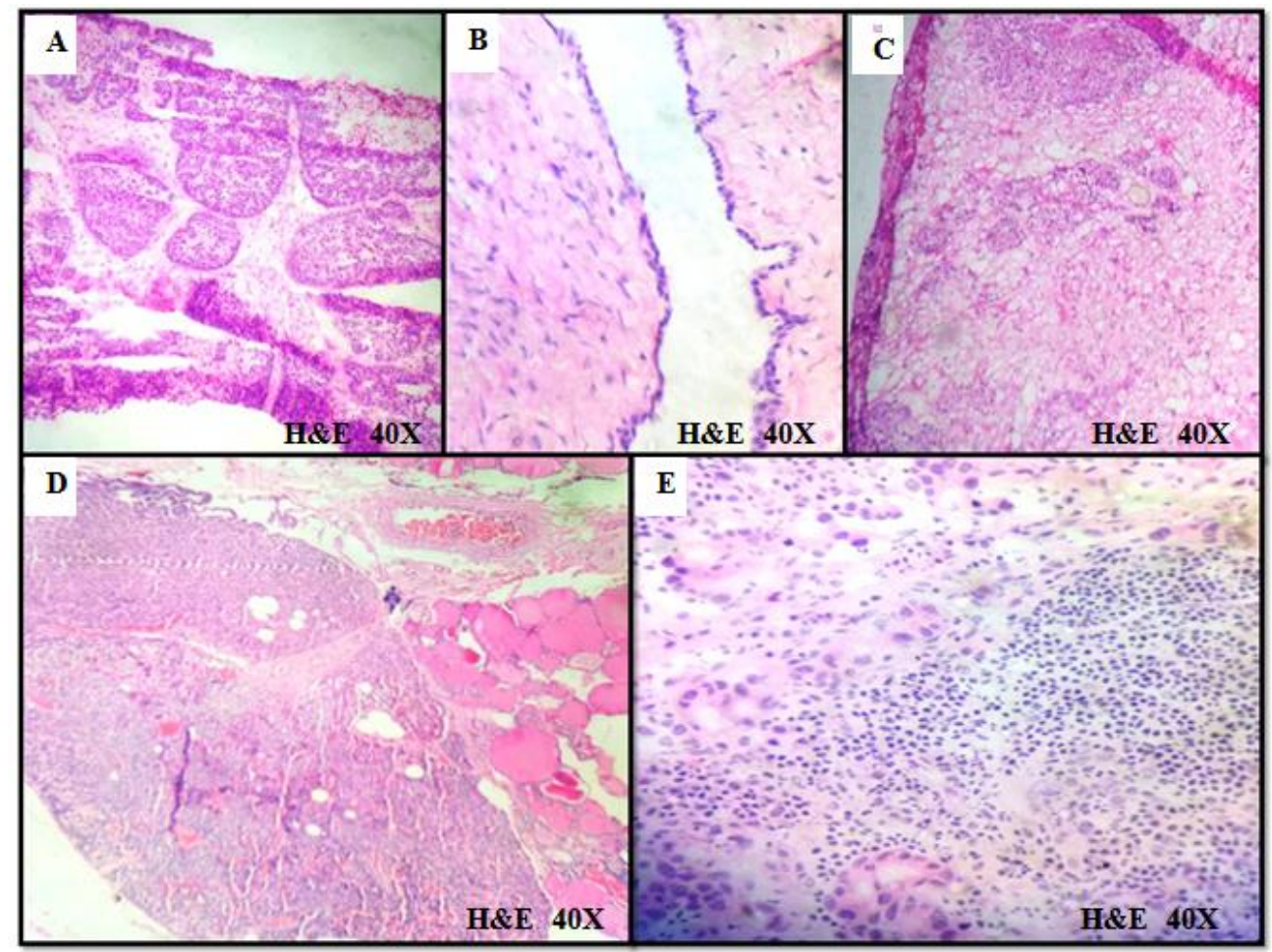

Fig. 4: Some of the diagnoses made by FS. A): Adenocarcinoma; B): Serous cystadenoma ovary; C): Margin involvement by tumor cells in an oral cavity carcinoma; D): Parathyroid organ identification; E): Lymphnode metastasis by malignant squamous cell 


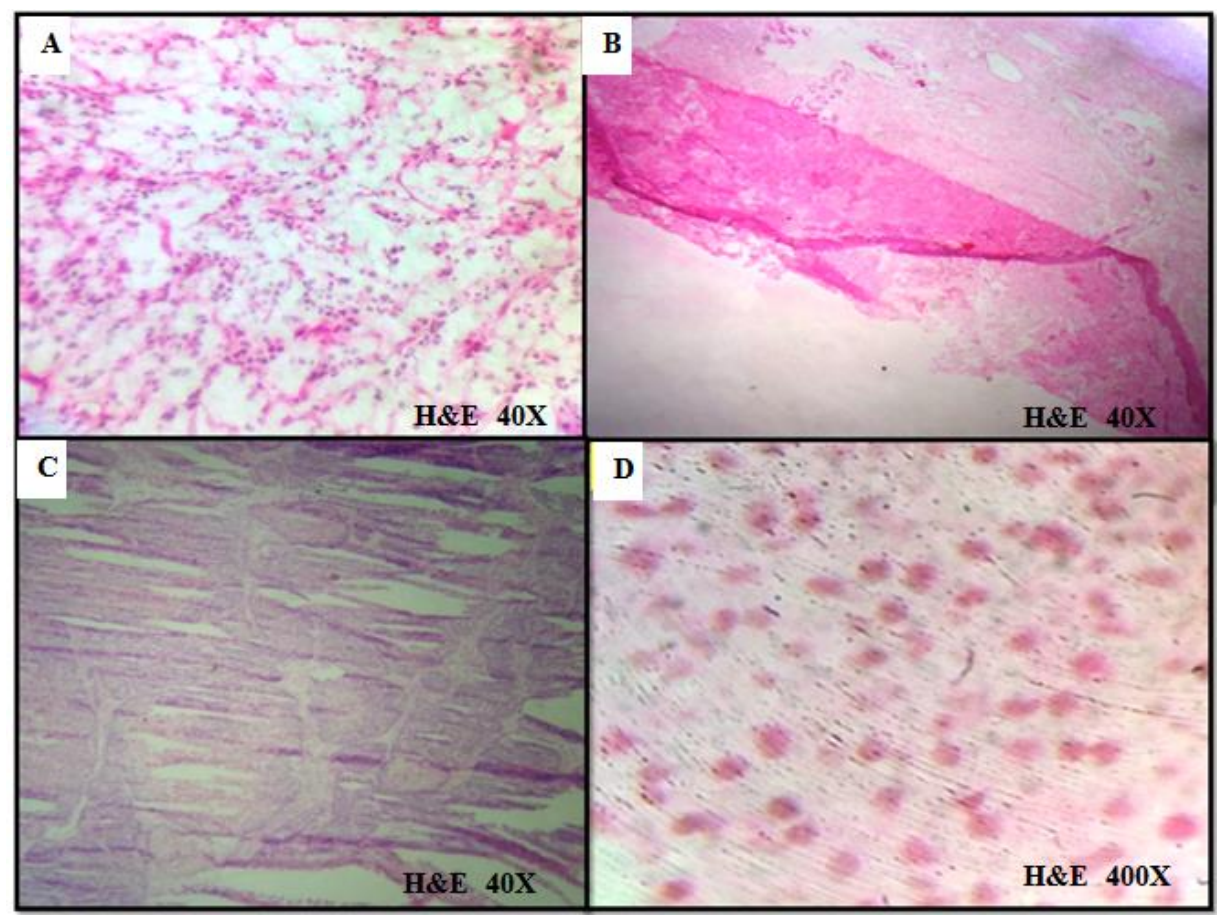

Fig. 5: A. Freezing artefact; B. Folding artefact; C. Sectioning artefact; D. Poor quality of the nuclear morphology in a FS. (H\&E- Hematoxyllin and Eosin)

\section{Discussion}

Frozen section (FS) is one of the common and often a reliable lab investigation sought by the surgeons from a pathologist for an intraoperative consultation. ${ }^{1}$ In view of this some of the surgical counterparts prefer the term "intra-operative consultation" rather than "frozen-section examination."7 FS helps a surgeon to plan or even terminate a surgery having a direct impact on the patient's management. ${ }^{1,7}$ It also allows the preservation of tissue samples for further formalin fixed paraffin embedding (FFPE) and any ancillary techniques when needed. ${ }^{1}$ Preoperative FNA and intraoperative cytological analysis such as touch imprints or scrape preparations are supplementary to FS and when used along with FS can assist the pathologist in interpretation and can help to reduce the errors. ${ }^{8}$ Squash cytology is usually used in the neurological FS consultation whereas fluid cytology is used for cystic lesions. ${ }^{1}$ We did not study the comparison between any adjunct cytological techniques with FS data. FS test is a technically demanding one, which requires the necessary equipment (CRYOSTAT), sufficient staff adept with the necessary skills and expertise and experienced pathologist. ${ }^{8}$

The most common indications for frozen section in the present study was the assessment of margins (52.27\%) followed by the determination of lymph node metastases $17.42 \%$ and presence/typing of neoplasms to rule out malignancy (13.64\%). However some of the studies showed presence/typing of the neoplasms as the most common indication followed by margins assessment and lymph node metastases status (Fig.
4). ${ }^{3,4,9}$ Increased usage of tobacco (gutka and khaini) has resulted in more frequent oral cancer in our country. ${ }^{1}$ Adequate margin clearance is important as the tumor that recurs is usually aggressive with poor prognosis. ${ }^{4}$ Studies from the US have reported an accuracy rate in margins interpretation in oral cancer varying from $71.3 \%$ to $97.5 \%$ and we had a comparable accuracy rate of $94.20 \% .1,10$

Regular quality checks by analysing the discordance rates between FS and the FFPE tissue diagnosis will not only help in identifying the common areas of errors but also to assess the prevailing workload, reveal the complexity of the procedure involved and to identify the dependability of the test concerned. ${ }^{5}$ The assessment also helps in formulating necessary decisions related to lab accreditation. ${ }^{5}$ The total number of concordant and discordant cases in our analysis was $125(94.70 \%)$ and $7(5.30 \%)$ respectively. The discordant rates in various studies range from $1.4 \%$ to $12.9 \%$ from different anatomical sites and the present study had a comparable data (Table 5). ${ }^{3,4,11,12}$ Errors may occur in any one of the multiple steps involved right from the specimen surgical resection, transportation, tissue processing, slide reporting till the report communication and discordant results are usually attributed to both interpretation and sampling errors, followed by technical errors such as sectioning, staining, and labelling. ${ }^{4,9}$

In our study interpretation errors $(3.79 \%)$ were the most frequently observed and was attributed to sectioning artefacts (freezing and folding), lack/poor quality of morphological details and presence of the diagnostic area only in the deeper sections (Fig. 5). FS 
interpretation is relatively more difficult and the overall morphology and histological quality is low especially in inflamed, edematous and fatty tissues when compared to formalin fixed paraffin embedded tissue (FFPE) sections. ${ }^{4}$ These errors can be avoided with adequate technical training given to the technicians and by using standard quality equipments. ${ }^{4,13}$ Freezing artefacts like nucleomegaly can be overcome by careful low power examination and their evaluation may be challenging especially in the presence/typing of a neoplasm. ${ }^{1,4}$

Meticulous examination and ordering of additional sections help in error reduction as incorrect FS reports may even attract litigations. ${ }^{1,4}$ Sampling of non diagnostic areas intra-operatively was the reason of the sampling errors $(1.51 \%)$. Prior appointment, better rapport and frequent discussions with the surgeons helped in getting the required clinical details and keeping the sampling errors to a minimum. Patil $\mathrm{P}$ et al ${ }^{3}$ had reported sampling errors of $1.0 \%$ and interpretation errors of $2.0 \%$ while Evans $\mathrm{CA}$ et $\mathrm{al},{ }^{14}$ reported sampling errors of $0.4 \%$ and interpretation errors of $0.8 \%$ in their respective studies. Our study had comparable results. The reported accuracy rates of FS diagnoses vary from 88.9 to $98.9 \%$ while the error rates range is 0.7 to $2.5 \%$ and the present study showed an accuracy rate of $98.65 \%$ and error rate of $1.35 \%$ in the comparable range. ${ }^{8,15,16}$ The above accuracy rate was obtained with sensitivity (true positive/true positive + false negative) of $90.91 \%$ and a specificity (true negative/true negative + false positive) of $96.59 \%$ which stood comparable against the available literature. ${ }^{8}$ Awareness of the limitations of FS will help to make the test a highly sensitive and a specific test. ${ }^{4,17}$

Accurate FS diagnostic reports are critical for fertility-conserving surgeries in young women and have an impact on the morbidity and mortality of the patients. ${ }^{7}$ Different studies have reported accuracy rates of frozen section of ovarian tumours between $86 \%$ to $97 \%{ }^{2,18}$ Our study had 9 cases of ovarian lesions and the accuracy rate was $88.89 \%$. Representative tissue was not submitted in one of the discordant case which was later diagnosed in the final paraffin processed tissue. Accuracy rate of ovarian tumors can be impaired by the larger size and the multilocular nature of the tumor especially the mucinous variety. 7,19 Recommendations are available to take one section per $10 \mathrm{~cm}$ of the mass to overcome sampling errors. ${ }^{7,20}$

The importance of gross examination before FS is not better explained in any organ than in the FS of a thyroid papillary lesion which is because of the great macroscopic variations encountered in these lesions. ${ }^{21}$ Although few studies have explained about the difficulties encountered while examining a follicular lesion it is a valuable tool when the fine needle aspiration cytology is suggestive of the category of suspicious for malignancy as per Bethesda categorisation. ${ }^{21,22}$ There were no discordant results in our thyroid FS consultations 12(9.09\%). FS in a parathyroid surgery is helpful for tissue identification and to identify parathyroid lesions. ${ }^{21}$ Normal parathyroid glands measure several millimetres while parathyroid adenomas are usually larger tan to brown, circumscribed, sometimes encapsulated with a thin rim of non neoplastic parathyroid tissue. ${ }^{21}$ Few authors have explained the use of intraoperative parathyroid hormone assays having better utility over FS in their surgical management, but the view is not accepted widely. ${ }^{23} \mathrm{We}$ had no discordance in our 2(1.52\%) parathyroid FS consultations. Mirra et $\mathrm{al}^{24}$ reported that presence of $>5$ polymorphonuclear leucocytes (PML) per high power field in at least five separate microscopic fields had better correlation with deep infection. FS as a tool has relatively better specificity in identifying the presence of inflammation. ${ }^{25} \mathrm{We}$ had $6(4.55 \%)$ consultations from the orthopaedics department of which $3(2.28 \%)$ were consulted for presence of inflammation and all the three showed evidence of inflammation. However we did not correlate with culture evaluation.

When the situation demands a FS diagnosis can be deferred and the surgeon should be advised to proceed as though the test has not been performed. ${ }^{8}$ In the available literature the deferral rate varies from 0 to $6.1 \%$ and our study had a deferral rate of $2.27 \%{ }^{8,15}$ In all the cases that were deferred inadequate sampling was found out to be reason and the diagnosis was made in the final complete specimens. TAT depends upon factors such as specimen processing time and the reporting time. ${ }^{8}$ In a large study conducted which compared the FS turnaround times of 700 institutions suggested that $90 \%$ of turnaround time was within 20 minutes which would be an acceptable time for most centres. ${ }^{26}$ In our study $98.48 \%$ of the consultations had a turnaround time of 20 minutes. In the remaining cases (1.52\%) the TAT was between $20-30$ minutes and the delay was due to multiple sectioning and request for more adequate tissue from the surgeons. FS reporting must be quick for the effective usage of this valuable investigation. $^{8}$

\section{Conclusion}

The present study helped us in identifying the capabilities and limitations of frozen sections. The pros and cons of this essential investigation were useful in giving valuable inputs to our lab technicians who play a major role along with the pathologist in the successful usage of the test. It also highlighted the importance of periodic quality assessment in any laboratory required to improve the quality of the service provided. Frozen section plays a critical role in the surgical management by avoiding second surgeries and can be of great value to the surgeon when carried out keeping in mind all its limitations. A good understanding between the pathologists and surgeons is crucial in this context. 


\section{References}

1. Agarwal Preeti, Gupta Sameer, Singh Kulranjan, Sonkar Arun Abhinav, Rani Preeti, Yadav Sunita, Goel Madhu Mati. Intra-Operative Frozen Sections: Experience at A Tertiary Care Centre. Asian Pac J Cancer Pre. 2016;17 (12): 5057-5061.

2. Anthony AG. The Centennial Anniversary of the Frozen Section Technique at the Mayo Clinic. Arch Pathol Lab Med. December 2005;129:1532-1535.

3. Patil P, Shukla S, Bhake A, Hiwale K Accuracy of frozen section analysis in correlation with surgical pathology diagnosis. Int J Res Med Sci. 2015;3:399-404.

4. Saumya Mishra, Mamta Gupta, Vinay Bharat, Rani Bansal. Qualitative Comparative Study of Frozen Section with Routine Histological Technique. National Journal of Laboratory Medicine. 2016 April,2:44-50.

5. Etienne Mahe,Shamim Ara, Mona Bishara, Annie Kurian, Syeda Tauqir, Nafisa Ursani et al. Intraoperative pathology consultation: error, cause and impact. Can J Surg. 2013 June;56(3):E13-E18.

6. Raab SS, Tworek JA, Souers R, et al. The value of monitoring frozen section-permanent section correlation data over time. Arch Pathol Lab Med. 2006;130:337-42.

7. Arikan Ilker, Barut Aykut, Harma Muge, Harma Mehmet Ibrahim, Ozmen Bayar Ulku, Gezer Sener et al. Accuracy of intra-operative frozen section in the diagnosis of ovarian tumours. J Pak Med Assoc. 2011 September; 61(9):856-858.

8. J J Khoo. An Audit of Intraoperative Frozen Section in Johor. Med J Malaysia, 2004 March; 59(1):50-55.

9. Roy S, Parwani AV, Dhir R, Yousem SA, Kelly SM, Pantanowitz L. Frozen section diagnosis Is there discordance between what pathologists say and what surgeons hear?. Am J Clin Pathol. 2013;140:363-369.

10. DiNardo LJ, Lin J, Karageorge LS, Powers CN. Frozen section margins in head and neck cancer surgery. Laryngoscope. 2000;110:1773-1776.

11. Shrestha S, Lee MC, Dhakal H, Pun CB, Pradhan M, Basyal R et al. Comparative study of frozen section diagnoses with histopathology. Postgraduate medical journal of NAMS. 2009;9(2):1-5.

12. Chbani L, Mohamed S, Harmouch T, Fatemi HE, Amarti A. Quality assessment of intraoperative frozen sections: an analysis of 261 consecutive cases in a resource limited area: Morocco. Health. 2012;4(7):433-35.

13. Chandramouleeswari K, Yogambal M, Arunalatha P, Bose JC, Rajendran A. Frozen and paraffin sectionsComparative study highlighting the concordance and discordance rates in a tertiary care centre. IOSR Journal of Dental and Medical Sciences. 2013;12(5):26-30.
14. Evans CA, Suvarna SK. Intraoperative diagnosis using the frozen section technique. J Clin Pathol. 2006;59(3):334.

15. Oneson RH, Minke JA, Silverberg SG. Intraoperative Pathologic Consultation. An audit of 1000 recent consecutive cases. Am J Surg Pathol 1989;13(3):237-43.

16. Rogers C, Klatt EC, Chandrasoma P. Accuracy of frozen section diagnosis in a teaching hospital. Arch Pathol Lab Med 1987;111:514.

17. Mayun AA, Pindiga UH, Abubakar A. Frozen Section : The need for intra-operative consultation between the surgeon and the pathologist. BOMJ. 2006;3(2):1-2.

18. Geomini P, Bremer G, Kruitwagen R, Mol BW. Diagnostic accuracy of frozen section diagnosis of the adnexal mass: a metaanalysis. Gynecol Oncol 2005;96:19.

19. Baker P, Oliva E. A Practical approach to intraoperative consultation in gynecological pathology. Int J Gynecol Pathol 2008;27:353-365.

20. Wang KG, Chen TC, Wang TY, Yang YC, Su TH. Accuracy of frozen section diagnosis in gynecology. Gynecol Oncol 1998;70:105-110.

21. Rose CA, Thomas MW. Frozen Section of Thyroid and Parathyroid Specimens. Arch Pathol Lab Med. 2005 December; 129:1575-1584.

22. Bahadir C, Sabahattin A, Celal H, Bahattin B, Akin $\mathrm{O}$, Alper $\mathrm{C}$ et al. Frozen section in thyroid surgery: Is it a necessity?. Can J Surg. 2004; 47(1):29-33.

23. Perrier ND, Ituarte $\mathrm{P}$, Kikuchi $\mathrm{S}$, et al. Intraoperative parathyroid aspiration and parathyroid hormone assay as an alternative to frozen section for tissue identification. World J Surg. 2000;24:1319-1322.

24. Mirra JM, Amstutz HC, Matos M, et al. Joint tissues in prosthesis failure. ClinOrthop 1976;117:221-40.

25. Musso AD, Mohanty K, Spencer R-Jones. Role of frozen section histology in diagnosis of infection during revision arthroplasty. Postgrad Med J. 2003;79:590-593

26. Novis DA, Zarbo RJ. Interinstitutional comparison of frozen section turnaround time. A College of American Pathologists Q-Probes study of 32,868 frozen sections in 700 hospitals. Arch Pathol Lab Med 1997;121(6):559-67.

How to cite this article: Selvakumar AS, Rajalakshmi V, Sundaram KM. Intraoperative frozen section consultation- an audit in a tertiary care hospital. Ind J Pathol Oncol, 2018;5(3):421428. 